\title{
A "Tetralogia dos Amores Frustrados": amor e paixão no cinema de Oliveira
}

\author{
Maria do Rosário Lupi Bello
} Universidade Aberta (Lisboa)

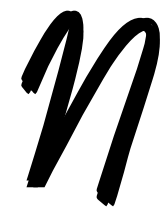

o início dos anos oitenta do século XX, o crítico de cinema e Director da Cinemateca Portuguesa, João Bénard da Costa, afirmava:

Se há casos de coragem moral neste País (e há-os, raros, mas alguns) Manoel de Oliveira é um dos maiores. E até sei que na amargura do que digo, ele, aparentemente pelo menos, não me segue. Por isso não o destruíram. Homens como ele não se destroem. Mas Oliveira fala também pelos muitos que ficaram destruídos. Ou frustrados, como os amores da sua tetralogia. Talvez também não seja por acaso que essas palavras - amor e frustração - vão juntas no seu cinema. Vão juntas em Portugal. Todos os nossos grandes amores se frustram. Destino geral? Talvez. Particular nosso? Certamente. ${ }^{1}$

Gostaria de começar este artigo concordando com a afirmação de Bénard da Costa sobre a coragem de Oliveira e sobre a portugalidade da sua abordagem à temática amorosa, procurando, ao mesmo tempo, responder à interrogação que coloca acerca da eventual universalidade da "frustração" dos grandes amores, tal como ela se apresenta no cinema deste

${ }^{1}$ AAVV, 1981, p. 6. 
realizador, em especial no conjunto dos quatro filmes que aqui são contemplados. Partilho a convicção sobre a grandeza de Manoel de Oliveira e sobre a sua profunda liberdade pessoal, que o tem feito percorrer um caminho próprio, contra ventos e marés, na absoluta fidelidade à sua intuição artística e existencial. Mas julgo não ser por acaso que a sua obra, mesmo quando aborda questões dramáticas, não ter laivos de amargura nem pessimismo. O desafio a que me proponho aqui é, pois, o de verificar se, como e porquê é possível filmar "amores frustrados" sem ceder ao puro sentimentalismo, ao melodrama radical, ou à negatividade auto-complacente. Fá-lo-ei não através da análise estrutural destes filmes, mas antes tomando em consideração este vector de significação que os agrega e procurando confrontá-lo com uma leitura global da obra do realizador, particularmente nas situações em que esta concepção emerge com maior evidência.

É necessário pois, antes de mais, olhar a questão em apreço - o amor e a paixão - tal como Oliveira a coloca. De todas as vezes que foi interrogado acerca dos "temas" da sua preferência, o cineasta escusou-se a enunciá-los, afirmando que o seu interesse se manifesta pela vida enquanto tal, pela existência enquanto experiência concreta, em vez de procurar apresentar problemas e temáticas de natureza abstracta ou teórica. Assim sendo, é preciso fazer-lhe a justiça, antes de mais, de considerar que o "amor" e a "paixão" de que tratam os seus filmes não são meros "temas" sobre os quais se interesse e debruce, mas antes fazem parte inalienável do tecido da existência, do humano na sua dimensão mais íntima, o qual Oliveira pretende captar com o seu cinema.

Faz parte da coragem moral deste cineasta, a que Bénard da Costa se refere, o uso frontal de palavras e conceitos "politicamente incorrectos" , fora das características da mentalidade dominante dos nossos dias; um deles é a constante defesa do objectivo da 
sua arte - a busca da "verdade". Bem longe da actual tendência ao esteticismo, que encerra a arte na torre de marfim que a supõe isolar do mundo, Manoel de Oliveira afirma repetidas vezes que na arte não há "santidade", e que ela, sendo fruto do trabalho do ser humano, é mero instrumento para a busca da essência misteriosa da realidade.

"Não se sabe o que seja a verdade", declara Oliveira a Antoine de Baecque e Jacques Parsi. "O artista avança no sentido da verdade, mas relata a ficção, isto é, o que imagina. Como quer apresentar o que diz como verdadeiro, recorre a referências verdadeiras, de modo a transmitir ao leitor a convicção de que o que ele vai ler é a verdade" ${ }^{\prime 2}$.

É, portanto, de ficção "verdadeira" que se ocupam os quatro filmes a que o cineasta chamou "Tetralogia dos Amores Frustrados": O Passado e o Presente (1972); Benilde ou a Virgem Mãe (1975), Amor de Perdição (1978) e Francisca (1981). Sendo todos eles baseados em obras literárias - os dois primeiros em peças de teatro, respectivamente de Vicente Sanches e de José Régio, e os segundos em romances, de Camilo Castelo Branco e de Agustina Bessa-Luís - pode afirmar-se que inauguram a tendência oliveiriana de fazer da literatura a fonte segura onde assentar a construção cinematográfica.

É sabido que o início da carreira de Manoel de Oliveira foi marcado pela importância dada ao documentário. A tal facto não é alheio o profundo interesse do cineasta pelo real, na sua dimensão concreta e palpável. Filmes como Douro, Faina Fluvial (1931), Estátuas de Lisboa (1932), Miramar, Praia das Rosas (1938), O Pintor e a Cidade (1956), O Pão (1966), fazem parte, entre outros, do gosto documental que caracteriza declaradamente a produção inicial do realizador. Com a "Tetralogia dos Amores Frustrados"

${ }^{2}$ BAECQUE; PARSI, 1999, p. 74-75. 
(que começou por consistir apenas em 3 filmes, aos quais o realizador acrescentou depois Francisca) tem início a grande aposta na inspiração literária, que dominará quase toda a sua obra, seguida e intercalada pela entrada no grande espólio cultural que é a História e a Mitologia de Portugal - de que Palavra e Utopia (2000), O Quinto Império (2004) e Cristóvão Colombo (2007) são bons exemplos, apenas interrompida por alguns filmes que se assumem mais "privados" e confessionais, como Viagem ao Princípio do Mundo (1997) e Je rentre à la Maison/Vou para casa (2001). Ao longo de toda a obra é possível reconhecer a importância da dimensão histórica do seu cinema (mesmo quando tal atributo é identificado com o valor objectivo da obra literária em que se baseia ${ }^{3}$ ), de onde ressalta um gosto evidente pela realidade cultural a que pertence - Portugal - tomada, porém, no seu sentido mais universalizante, ou seja, partindo de situações, locais, figuras portuguesas sobre as quais incide um olhar e uma reflexão que, de tal forma vão longe e fundo, que saltam as fronteiras nacionais, remetendo para um património que é o de toda a humanidade.

Por isso faz sentido partir do juízo inicial de Bénard da Costa, já que este crítico, a propósito de Manoel de Oliveira, associa uma característica eminentemente portuguesa à possibilidade de um dado universal - será a natureza dos grandes amores a de não poderem verdadeiramente realizarse? Que nos diz, e como, o cinema de Manoel de Oliveira sobre essa realidade?

\footnotetext{
3 "Eu tomo a palavra histórico em relação ao livro", diz Oliveira a propósito da adaptação de Amor de Perdição. "O livro é uma obra de ficção, mas cuja fonte é real. Camilo parte de uma verdade, mas faz ficção, que é o espelho da verdade". (BAECQUE; PARSI, 1999, p. 76).
} 
Os quatro filmes que compõem a sua tetralogia encontramse intimamente ligados, tanto a nível da questão de fundo - a problemática do amor entre homem e mulher - quanto no que diz respeito à idêntica visão que dela têm os vários artistas: Camilo Castelo Branco, Vicente Sanches, José Régio, Agustina Bessa-Luís e o próprio Manoel de Oliveira. Na verdade, é visível em cada um destes autores uma concepção da relação amorosa como dramática, em sentido etimológico, ou seja, luta sem tréguas para atingir um ideal que parece sempre ultimamente escapar, a menos que seja projectado num âmbito para além da morte. Senão vejamos.

No caso de $O$ Passado e o Presente, a impossibilidade da realização plena do amor toma corpo na obsessão necrófila de uma mulher de alta sociedade, citadina e sofisticada, que só consegue verdadeiramente apaixonar-se pelos maridos que tem depois de estes morrerem. Amor e morte ligam-se aqui de forma explícita, numa alusão clara à única condição que permite a plena e total satisfação amorosa: a dimensão transcendente, evocada, neste filme marcado por uma mobilidade de câmara muito superior à habitual em Oliveira, de um modo eminentemente fúnebre. Filme onde os corpos e o amor erótico se evidenciam em cada situação, O Passado e o Presente remete o espectador para o conflito entre a carnalidade de que é tecido o amor conjugal, por um lado, e a dimensão imaterial que verdadeiramente o cumpre, assim representand o tanto a dramática luta contra a morte quanto a atracção por ela enquanto único lugar da plena união.

Com Benilde ou a Virgem Mãe - que Manoel de Oliveira adapta a partir da peça homónima de Régio, de 1947, filmando esta versão depois de Abril de 74, em plena época revolucionária, quando a esmagadora maioria dos realizadores portugueses se ocupa de obras de intervenção política - a transcendência do amor assume claramente a sua conotação religiosa. Benilde é 
uma rapariga burguesa que vive na província, solteira e virgem, e que acredita ter engravidado por via sobrenatural. Perante a sua inabalável convicção, tanto aqueles que com ela convivem, como nós, os espectadores, somos convocados a uma tomada de posição sobre esse extraordinário facto, o qual exige que tanto a razão como a fé sejam tomadas em consideração, a fim de que cada um tire, por si mesmo, a conclusão que considerar mais plausível. Num cenário que se assume explicitamente teatral, tornando visíveis os aspectos de representação artística (já que é o "teatro da vida" que importa captar), toma, assim, lugar um drama que vai ao fundo da raiz da experiência humana: o dado mais decisivo da vida - que um ser humano dê vida a outro ser humano - escapa ao pleno domínio e à plena compreensão do homem e da mulher.

Com o filme Amor de Perdição, Oliveira radicaliza a visão camiliana do amor. Se o romancista dera à sua novela o cunho de uma dramática batalha contra a brevidade e implacabilidade de um tempo (um tempo social, um tempo cronológico, um tempo psicológico) que se revela inimigo dos amantes, em luta contra tudo e contra todos, já o cineasta torna claro desde o início da sua obra que esse é o tempo trágico da impossibilidade da consumação amorosa. Na cena em que Simão vê o pai de Teresa afastá-la violentamente da janela, o jovem apaixonado lança-se sobre a cama do seu quarto, deixando cair um braço, que permanece inerte, na posição de uma terrível certeza: a de que não há batalha que possa resgatar a sua amada das garras de um destino inelutável. O protagonista do filme é um homem (con)vencido, quase desde o princípio, por essa intuição última de que tal amor, tão imenso que é, não poderá ter, na terra, lugar de realização efectiva. Teresa é quem dá voz a essa certeza de que só o céu é lugar da plena pertença mútua, através das cartas onde aponta o horizonte último das "estrelas" ("Estou tranquila... Vejo a aurora da paz... Adeus, até ao céu, Simão"), certeza essa 
que Simão tem dificuldade em viver, e que Mariana liminarmente recusa.

Quanto a Francisca, essa é a história das mil e uma complexas ambiguidades e dos muitos desencontros que a paixão - aqui enquadrada no terrível triângulo amoroso entre Fanny Owen, Camilo Castelo Branco e José Augusto Pinto de Magalhães pode desencadear. E é também a história onde Agustina afirma (e Oliveira com ela) que "a alma é um vício" - não é possível não viver a dimensão que a alma instaura, tal como não é possível estar vivo sem respirar o ar que a todos rodeia, ainda que isso implique correr todos os riscos, inclusivé o da própria destruição . A um vício, por definição, não se escapa, e o vício da alma é o mais "tirânico" de todos.

A ideia-base, que preside a cada uma destas obras, assenta, por um lado, na convicção oliveiriana de que o amor homem-mulher revela uma incomunicabilidade última que a condição existencial de contingência do ser humano não pode resolver e, por outro lado, na afirmação de que o amor absoluto, a que a alma não pode deixar de aspirar, não é alcançável durante a existência terrena.

Diz o realizador a propósito da sua tetralogia, ao longo da qual vai glosando a infinidade de matizes com que essa incomunicabilidade e essa intangibilidade se exprimem através da relação explícita do amor com a morte, através da componente transcendente e mesmo milagrosa do amor, através da impossibilidade de concretização "social" da paixão, através da ambiguidade das relações, etc, etc:

Tem graça, pois foi a partir de O Passado e o Presente que pensei em filmar Benilde e, depois, Amor de Perdição. Achei que havia um fio comum tratado em todos esses livros: uma certa impossibilidade de atingir o amor absoluto... Ou, por outras palavras, tal amor será extra-terreno! A partir dessa ligação, em três histórias completamente diversas, embora 
todas com situações caprichosas, ao nível social e religioso, chega-se à mesma conclusão, mas por ordens diferentes, com um fundo comum. Será interessante saber-se que, sendo $O$ Passado e o Presente a última destas obras em termos de escrita, o autor teria influências e era grande admirador do José Régio. Por sua vez, Régio confessava o seu profundo apreço por Camilo Castelo Branco, cujos livros conservava à cabeceira... Por tudo isto me parece tão interessante como, ao transpor O Passado e o Presente, eu senti a Benilde e o Amor de Perdição, com necessidade de os concretizar em cinema. $\mathrm{O}$ que veio a acontecer, numa série sobre amores frustrados, culminada depois em tetralogia, com Francisca. ${ }^{4}$

É, na verdade, pertinente saber que Oliveira "leu" Camilo e Régio "através" de Vicente Sanches, e que o vector com que ligou tais escritores radicou, para Oliveira, nessa concepção de frustração do amor. Mas há outro autor, não português, que o cineasta associa à mesma leitura que faz do amor não plenamente realizado: Paul Claudel.

Há um aspecto comum entre Le Soulier de Satin e os meus filmes da "tetralogia dos amores frustrados", por certas atitudes nas relações amorosas e pela dificuldade que o homem e a mulher encontram em se reconhecerem de maneira absoluta. ${ }^{5}$

O problema tem, portanto, que ver com uma dificuldade de (re)conhecimento mútuo: é como se o homem e a mulher fossem incapazes de verdadeiramente descobrirem a identidade um do outro, bem como de se relacionarem com essa identidadeoutra. Tal reconhecimento dá-se, portanto, de forma sempre

\footnotetext{
${ }^{4}$ MATOS-CRUZ, 1996, p. 32-33.

${ }^{5}$ BAECQUE; PARSI, 1990, p. 84.
} 
dolorosa e ambiguamente parcelar, incompleta, confusa, problemática. Por isso, acrescenta o realizador, durante esta mesma entrevista: "Pode-se sempre citar um caso ou outro, mas é muito difícil obter uma opinião definitiva sobre o homem ou a mulher que, no fundo, continuam, após tantos anos, a ser desconhecidos". ${ }^{6}$

Desse desconhecimento profundo nasce a frustração, a dor, a tragédia. Ou, para dizer com maior rigor, usando as palavras de George Steiner - é o trágico que nasce deste desentendimento, e não a tragédia, é o trágico que é universal. A tragédia, de raízes gregas e shakespeareanas, exprime-se através de uma forma artística específica, que o nosso tempo desvalorizou (e que Steiner considera só subsistir no Japão). Porém, o elemento trágico acompanha sempre a humanidade, enquanto manifestação do insolúvel, daquilo que - pelo menos aparentemente - parece ser a impossibilidade de realização plena de um desejo inalienável.

É precisamente isto que a Tetralogia de Oliveira significa: a constatação de que homem e mulher se desejam porque desejam uma unidade nunca plenamente conseguida, a unidade dessa espécie de forma "andrógina" original que para sempre se perdeu, embora permaneça como ideal a atingir. E é a experiência desta aparente impossibilidade que exacerba mais o amor, levando os amantes ao sacrifício de tudo - até da própria vida, como em Amor de Perdição - por puro amor. Oliveira exprime, deste modo, a sua convicção de que o desejo mais profundamente humano é de uma dimensão incomensurável, indizível, infinita, mais forte que a vida e mais forte que a morte.

${ }^{6}$ BAECQUE; PARSI, 1990, p. 111. 
Na verdade, tal como em Camilo Castelo Branco, também em Manoel de Oliveira é o desejo um conceito-chave ${ }^{7}$. E julgamos que nele tal conceito assume a plena potencialidade da sua etimologia, da qual ressalta a intrínseca relação entre desejo e dor. Desiderium decompõe-se em dois vocábulos - de (ausência de; negação; falta de) e siderium (o cosmos, espaço sideral). Desejar é, pois, em última análise, sentir a falta do cosmos, das estrelas, do Todo, é ter sede desse Todo. Esta é a natureza do puro desejo, que se exprime, existencialmente, na multiplicidade e diversidade dos desejos particulares e concretos. Se o desejo é "falta", a ele se encontra sempre, de algum modo, aliada a dor, uma dor que é como que a melancolia por um Bem ausente ou desconhecido ${ }^{8}$, existente numa dimensão que não a terrena.

Não admira, portanto, que Manoel de Oliveira associe o amor ao sacrifício, apostando em figuras femininas que se sacrificam por amor. É sabido que Oliveira tem da figura da mulher uma concepção muito própria. Baecque e Parsi ${ }^{9}$ consideram-no mesmo "um cineasta da mulher". E Oliveira, que gosta de frisar o lado mais digno e respeitável que vê até

${ }^{7}$ Remetemos aqui o leitor eventualmente interessado para o artigo " "Amar até doer". O Desejo do Amor e a Perdição dos Desejos», que publicámos em: SOUSA; MARTINS, 2010.

${ }^{8}$ A propósito de Francisca, Oliveira sublinha a profundidade dos diálogos, onde por vezes se exprime a natureza misteriosa do desejo humano, dando, entre outros, o exemplo da conversa entre José Augusto e Camilo, em que o primeiro diz "eles são bêbados, vão já pedir-me dinheiro para cigarros e vinho", ao que Camilo responde "isso é o que eles pedem, será isso o que eles querem?". E conclui Oliveira: "Estes são diálogos muito ricos de significação. Cf. AAVV, 1981, p. 43.

${ }^{9}$ BAECQUE; PARSI, 1999, p. 106. 
nas mulheres que se prostituem, sublinha a capacidade de redenção e de fé que nelas encontra, e que é capaz de, através do amor romântico, arrastar os homens ao bem ${ }^{10}$. Dando, em regra, às mulheres os papéis de maior potência nos filmes que realiza, o cineasta atribui-lhes uma força simultaneamente atractiva e destrutiva, tanto purificadora como perversa, através do poder de sedução que as pode habitar (como acontece com Ema de Vale Abraão). Mas, diferentemente de Camilo Castelo Branco, que submete o universo feminino ao peso de um fatalismo que quase não deixa margem à liberdade, e de Agustina Bessa-Luís, que prefere quase sempre explorar a força misteriosa e dominadora que a feminilidade revela, Oliveira concentra-se frequentemente na capacidade de sofrimento da mulher, ser doador de uma entrega amorosa, capaz de sacrifício e de uma paixão que nunca vê plenamente cumpridas. Traços deste sacrifício são visíveis em Wanda, tal como em Benilde, em Teresa e Mariana, e obviamente também em Fanny Owen.

E não é, também, por acaso que tais heroínas são frequentemente mulheres virgens. Benilde tem a virgindade "mariana", é o rosto do mistério maior; tanto a Teresa como a Mariana de Amor de Perdição são mulheres que não experimentam a dimensão física do seu amor; Fanny Owen é o exemplo gritante de um casamento não consumado; e mesmo a insinuante Wanda, de O Passado e o Presente, afirma a preponderância do amor não carnal, ao manifestar a sua paixão pelos maridos já mortos, a sua dedicação a imagens e corpos sem vida. Interrogado sobre esta questão, Oliveira recusa frontalmente a ideia de que esse tratamento da virgindade consista num gosto teórico pelo bizarro ou pelo doentio, afirmando antes o valor real e positivo de tal escolha.

${ }^{10}$ BAECQUE; PARSI, 1999, p. 108-109. 
Assim, perante a pergunta de João Bénard da Costa acerca da destruição a que são conduzidas muitas das personagens oliveirianas, porque, "quando fala de amor, junta-lhe a perdição", responde o cineasta: "Não falo de coisas abstractas, falo de coisas concretas (o que se passou com o Simão e a Teresa passou-se assim)". E em seguida, quando, ao longo da mesma conversa, Manuel S. Fonseca afirma que Oliveira associa a paixão à doença, da qual o tema da virgindade é exemplo, perguntando: "Este tema da doença é-lhe particularmente grato e acha que de facto está lá?", o realizador contesta: "Sim, só que eu não a tomo por doença. As coisas às vezes deslocam-se; chama-se doente a um herói, a um revolucionário que perde a sua vida; chama-se doença àquilo que não dá resultado prático, útil, lógico" ${ }^{11}$

É, portanto, de outra dimensão a natureza deste amor virginal. A leitura simplista que o vê como mero gosto em retratar figuras doentias ou excêntricas não faz justiça a Oliveira. O realizador parte daquilo que vê, dos casos concretos da vida e da arte, para tirar ilações acerca do humano - de um humano marcado por um desejo que nada, nem sequer a relação amorosa mais intensa pode, por si mesma, saciar. É pela natureza inesgotável, infinita, "impossível" deste amor - que a sociedade julga poder dominar, embora ultimamente seja impotente para o fazer - que o artista Manoel de Oliveira se interessa incansavelmente:

O que leva [os heróis de Amor de Perdição] à morte não é o amor, é a sociedade. Eles não são propriamente suicidas. Não se matam, só que não encontram soluções e são prisioneiros (é muito bonito esse amor de prisão porque eles prendem o próprio corpo como se pretendessem prender a alma). Um é prisioneiro no convento, outro é prisioneiro

${ }^{11}$ AAVV, 1981, p. 42. 
na cadeia; prendem-lhes os corpos como se pretendessem prender-lhes a alma, mas não podem: eles no fundo são livres, são livres de amar, de desejar. O corpo deles é submetido pelos carrascos, não por eles próprios, eles desejam-se. A tendência dos amorosos é unir-se. Quando as paixões são exacerbadas e loucas, querem também unir as almas. A união das almas é impossível, só com a morte. O que seduz o homem é o impossível (atractivo e deslumbrante). ${ }^{12}$

E aqui está como a expressão da paixão impossível é, para Oliveira, uma afirmação positiva ("atractiva, deslumbrante") de totalidade, mesmo quando implica a virgindade, mesmo quando implica a morte. Tanto uma como outra são sinal de uma união que vai para além da carne, que se afirma noutra dimensão. Oliveira fala do valor da "impossibilidade", do mecanismo humano que leva um homem a desejar sempre mais, e tanto mais quanto mais "impossível" parece ser o objectivo. A esperança de satisfazer um desejo é a condição do humano, mas desejar, por si mesmo, não resolve o problema, pelo contrário: a consciência da natureza insaciável desse desejo antes o agudiza, intensifica-o, tal como aumenta a sede do homem perdido no deserto que, a certa altura, entrevê o longínquo oásis. Só a abertura até ao infinito, o estabelecimento da sua natural relação com o Mistério, e portanto a confiança última de poder alcançar a fonte, permite percorrer humanamente os quilómetros que faltam, a fim de verificar o cumprimento da promessa que o desejo contém.

Esta é precisamente a razão pela qual o cinema de Oliveira, mesmo quando fala de sofrimento, não se deixa enclausurar em quaisquer tipos de negativismos ou - ainda menos - numa qualquer teorização da amargura, como se vê

12 AAVV, 1981, p. 42. 
acontecer em algum cinema português. O seu olhar é rasgado, livre, de longo alcance, e portanto, aberto até às implicações últimas. Disto mesmo falou recentemente o realizador em Lisboa, no Centro Cultural de Belém, diante do Papa Bento XVI e de muitos intelectuais, professores, artistas. Assumindo a sua formação cristã e retomando as palavras do Padre António Vieira ("terrível palavra é o non"), que deram o título ao filme que realizou em 1990 (Non ou a vã glória de mandar), Oliveira considerou: "Acossados pelas especulações da razão, sempre se nos levantam terríveis dúvidas e descrenças, a que se procura opor a fé do Evangelho, que remove montanhas". Perante a tremenda hipótese da negação, o cineasta concluiu, com a convicção de quem fala de um caminho trilhado na primeira pessoa: "o 'non' retira toda a esperança, que é a última coisa que a natureza deixou ao homem", a esse mesmo homem que "caminha na esperança, apesar de todos os negativismos". A certeza de que a dinâmica humana é afirmativa, só podendo ser travada por uma escolha teórica e teorizada, que não corresponde ao dinamismo que leva o ser humano a esperar e a desejar (desejar viver, desejar amar e ser amado, desejar criar, desejar ser feliz) encontra, de facto, na pessoa de um homem de 101 anos, de olhar vivo, quase infantil, com uma capacidade criativa absolutamente invulgar e uma liberdade de pensamento e acção que fazem dele uma criatura "sui generis" e incómoda no universo em que se movimenta, um inegável testemunho da verdade do que afirmou.

Mas seria injusto ver nesta posição de Oliveira uma qualquer forma de proselitismo religioso. Comentando o filme português de José Fonseca e Costa, Cinco Dias Cinco Noites (1996), baseado num romance de Manuel Tiago (o líder comunista Álvaro Cunhal), afirma Oliveira: 
É sobre o homem perseguido, e termina de uma maneira vaga, não há política nele. Há um certo humanismo, que é a sua principal qualidade. Nenhum filme tem que defender política nenhuma, nem religião nenhuma. Embora os comunistas sigam a par e passo o catecismo católico, de que a arte deveria - de resto, o próprio Paul Claudel também professava isso - defender a religião. É um erro. A arte não tem que defender coisa nenhuma. A arte tem que expressar aquilo que se sente. É um fundamento humanista. Não tem de fazer propaganda. ${ }^{13}$

É, pois, importante compreender a lealdade para com a existência que ressalta desta visão de Oliveira. O realizador não aborda tais questões por serem "temas" do seu agrado, como já vimos, nem faz deles pretexto ou veículo para expressão de crenças pessoais. Limita-se a representar aquilo que vê e sente, por ser essa a tarefa que acredita pertencer ao artista verdadeiro.

Também acerca de um dos realizadores que mais admira, o dinamarquês Carl Dreyer, autor de Gertrud (1964), que afirmava que "a alma é revelada no estilo", diz o cineasta português (referindo-se precisamente a esse filme):

É o filme mais fantástico de todos os tempos que eu jamais vi. Toca o absoluto. É sobre uma dama que quer o amor absoluto, mas este não se encontra nesta vida. Acusavam o Dreyer de ser religioso, por ter feito o milagre ["A Palavra", 1955]. Mas aqui não. É a procura do amor absoluto. É a relação de um escritor com a sua mulher, que ele acusa de perturbar a sua escrita. Ela percebe que ele não a ama verdadeiramente, e recusa-o. Ela amava-o, mas ele não a amava. E, no final, em vez de tocar o relógio, tocam os sinos. É a morte, onde ela encontra o amor absoluto. ${ }^{14}$

${ }^{13}$ ANDRADE, 2008, p. 54.

${ }^{14}$ ANDRADE, 2008, p. 52. 
Se é verdade que este fascínio pela morte como possibilidade última caracteriza muita da literatura portuguesa, ela é, obviamente, encontrável na literatura e na arte universal, já que exprime, acima de tudo, o desejo de tocar o absoluto. Retomando a frase inicial de João Bénard da Costa, é possível concluir que a representação desta não plenitude do amor terreno se afirma em Oliveira sem quaisquer cedências quer a uma "ideologia" de tipo religioso ou moral, quer a um pessimismo sentimental ou melodramático. A razão desta natureza "enxuta" e límpida da arte oliveiriana radica portanto, na minha opinião, num duplo factor: por um lado, na coragem que o realizador tem de nunca fazer do seu cinema um lugar de especulação ideológica, aceitando, antes, que seja a própria realidade a suscitar o percurso total daquilo que ele próprio exprime, em vez de aplicar um qualquer tipo de "grelha" prévia, que a arte deva "demonstrar". E, por outro lado, no imparável gosto pela existência que Manoel de Oliveira evidencia (e de que o seu mais recente filme, Singularidades de uma rapariga loura é exemplo tão flagrante), aliado a uma notável capacidade de não se levar muito a sério. $O$ traço de ironia que perpassa a sua longa obra - e que João Lopes sublinha existir na Tetralogia, paralelamente ao que considera ser um certo "fatalismo"15 testemunha essa inteligente capacidade de sorrir do que é passageiro para se concentrar na seriedade e dramaticidade do que fala do absoluto. Tal como Bresson, o realizador francês que Oliveira tanto aprecia, o cineasta português quer "dar a ver" o "interior" das coisas, através do seu específico modo de filmar

${ }^{15}$ Diz J. L. no "Diálogo com Manoel de Oliveira", pertencente ao catálogo da Cinemateca Portuguesa Manoel de Oliveira. Lisboa: Cinemateca Portuguesa, 1981, p. 43: “Eu refiro isto porque suponho que na Tetralogia há um elemento muito forte, paralelo a esse fatalismo, que é um elemento irónico". 
o "fora" dos objectos. Por isso, interessa-lhe a abordagem documental, aquela que possa preservar o aspecto de verdade do mundo que filma, uma verdade que, captada com precisão, revele, na aparência imanente das coisas, a sua dimensão transcendente, isto é, a precisão do real, como diz Paul Schrader a propósito de Bresson: "The supernatural in film is only the real rendered more precise. Real things seen close up". 16

José Régio foi, como se sabe, além de amigo pessoal de Manoel de Oliveira e artista muito admirado por este, dos primeiros que, em Portugal, soube reconhecer o talento do realizador. No texto que foi publicado em 1963 no jornal $O$ Comércio do Porto, disse o escritor e poeta de Vila do Conde, com quem o realizador partilhava tanto aquilo que definiu como "um espírito religioso atormentado pela dúvida" quanto esta visão simultaneamente sofrida e escancarada até ao infinito do amor passional:

Este poeta - este intuitivo - é um intelectual, que nem sempre organiza ou consciencializa disciplinarmente as suas intelecções; um contemplativo mas não incapaz de intervir; um filósofo sem filosofia nem método, seria eu tentado a dizer, se não receasse abusar dum tom meio lúdico meio sério. Não sei se é isto mau ou tanto melhor. $\mathrm{O}$ que sei é que o exigentíssimo artista que há em Manuel de Oliveira - sempre tão descontente ou inquieto, ou duvidoso entre soluções diversas, ou atormentado pela sua própria riqueza - sabe aproveitar muito bem as suas perplexidades, e até os acasos que se lhe oferecem. Decerto pode o acaso ser um excelente colaborador do realizador de cinema, quando este o mereça. ${ }^{17}$

16 SCHRADER, 1988, p. 62.

${ }^{17}$ LOUREIRO; PINTO, 2010, p. 113. 
Para Oliveira o acaso é, como ele gosta de repetir, citando Luiz Francisco Rebello, a máscara do destino. E é essa a razão pela qual o realizador não demonstra medo nem cinismo quando decide filmar essa sequência de quatro obras onde representa a frustração do amor, entendido como bem absoluto, remetendo assim o espectador, de forma provocatória, para a consideração do nível mais profundo que a visibilidade dessas histórias documenta.

\section{Bibliografia}

AAVV - Manoel de Oliveira. Catálogo da Cinemateca Portuguesa. Lisboa: Cinemateca Portuguesa, 1981.

ANDRADE, Sérgio C. Ao Correr do Tempo. Duas décadas com Manoel de Oliveira. Lisboa: Portugália Editora, 2008.

BAECQUE, Antoine de; PARSI, Jacques. Conversas com Manoel de Oliveira. Porto: Campo das Letras, 1999.

LOUREIRO, Filipa; PINTO, Paulo. Manoel de Oliveira/José Régio. Vila do Conde: Câmara Municipal de Vila do Conde-Museu de Arte Contemporânea de Serralves, 2010.

MATOS-CRUZ, José de. Manoel de Oliveira e a Montra das Tentações. Lisboa: Publicações D. Quixote, 1996.

SCHRADER, Paul. Transcendental Style in Film. Ozu, Bresson, Dreyer. Berkeley: Da Capo Press, 1988.

SOUSA, Sérgio Guimarães de; MARTINS, José Cândido de Oliveira (Org). Leituras do Desejo em Camilo Castelo Branco. Braga: Editora Opera Omnia, 2010. 


\section{Resumo}

Com este artigo pretende-se evidenciar o modo como Manoel de Oliveira trata a questão do amor humano, não fazendo dele mero "tema" da sua obra, mas antes representando-o enquanto realidade concreta e dramática, cujos sentido e verdade deseja captar fielmente. Através das quatro obras da sua "Tetralogia dos Amores Frustrados" (que incluem os filmes O Passado e o Presente, Benilde ou a Virgem Mãe, Amor de Perdição e Francisca, todos eles baseados em obras da literatura portuguesa), o cineasta exprime aquela que considera ser a incomunicabilidade última da relação entre homem e mulher, bem como a intangibilidade do amor absoluto. Apesar da dramaticidade desta visão, os filmes de Oliveira não resultam em obras negativas ou pessimistas, nem marcadas por um tom sentimental ou radicalmente melodramático, já que o realizador nelas evidencia uma constante ironia testemunho de uma capacidade de sorrir do acessório para sublinhar o essencial -, bem como testemunha, acima de tudo, a percepção positiva da incomensurabilidade do desejo como forma de remeter para o infinito. Deste modo, a sua obra, marcada por um gosto assumidamente português, extravasa as fronteiras nacionais para se relacionar com a arte universal naquilo que ela exprime de mais profundamente humano.

\section{Abstract}

This article aims to underline the way Manoel de Oliveira deals with the issue of human love, not as a mere "theme" or "issue" in his work, but instead representing it as a concrete and dramatic reality, which sense and truth he wishes to capture faithfully. Through the four films that constitute his "Tetralogia dos Amores Frustrados" (including O Passado e o Presente, Benilde ou a Virgem Mãe, 
Amor de Perdição and Francisca, all of them based upon portuguese literary works), the director expresses the ultimate impossibility of communication between man and woman, as well as the intangibility of absolute love. In spite of the dramatic content of this specific vision, Oliveira's movies are not negative or pessimistic works, neither do they assume a rather sentimental or melodramatic tone, since the director expresses a constant irony - a testimony of his capacity of smiling upon what is accessory, so that the essential is rendered more evident - as well as testifies, above all, the positive perception of the incommensurability of human wish as a way of referring to the infinite. By doing so, his work, characterized by an evident Portuguese taste, transcends the national frontiers and relates to universal art in so far as it can be seen as an expression of that which is more profoundly human. 